\title{
Timing attention: Cuing target onset interval attenuates the attentional blink
}

\author{
SANDER MARTENS and ADDIE JOHNSON \\ University of Groningen, Groningen, the Netherlands
}

\begin{abstract}
Three experiments tested whether the attentional blink (AB; a deficit in reporting the second of two targets when it occurs 200-500 msec after the first) can be attenuated by providing information about the target onset asynchrony (TOA) of the second target relative to the first. Blocking the TOA did not improve second-target performance relative to a condition in which the TOA varied randomly from trial to trial (Experiment 1). In contrast, explicitly cuing the TOA on a trial-by-trial basis attenuated the $\mathrm{AB}$ without a cost to first-target identification (Experiments 2 and 3). The results suggest that temporal cues influence the allocation of attentional resources by adding temporal information to the perceptual description of the second target that can then be used to filter targets from nontargets, resulting in enhanced accuracy.
\end{abstract}

The visual system is remarkably efficient at picking up information from the outside world. For example, it takes only a fraction of a second for one to feel embarrassed when walking into the wrong room. Despite people's seemingly limitless ability to process information and the speed at which the gist of any given scene can be extracted, the ability to report the details of incoming information is severely restricted. Recent studies on a phenomenon called the attentional blink (AB; a deficit in reporting the second of two targets presented in rapid serial visual presentation [RSVP] when it occurs 200-500 msec after the first target; e.g., Raymond, Shapiro, \& Arnell, 1992) have shown that incoming information can be processed up to the level of semantic analysis, but that there is a bottleneck in transferring the information into working memory and in consolidating it so that it can be consciously used for the control of behavior (e.g., Luck, Vogel, \& Shapiro, 1996; Martens, Wolters, \& van Raamsdonk, 2002; Rolke, Heil, Streb, \& Hennighausen, 2001; Vogel, Luck, \& Shapiro, 1998). The question addressed in the three experiments reported here concerns whether strategic information can be used to overcome temporal limitations in consolidating information in working memory.

Since Broadbent and Broadbent (1987; Experiment 3) first demonstrated the relatively long-lasting interference effect resulting from target identification that has come to be known as the AB (Raymond et al., 1992), the $\mathrm{AB}$ paradigm has been used to study the costs of divid-

This research was supported by a grant from the Netherlands Organization for Scientific Research, awarded to A.J. We thank Jaap Munneke and Mineke Felten for assistance in running the experiments. We also thank Mary Potter, Stefan Debener, and Bernhard Hommel for their helpful comments on an earlier version of this article. Correspondence should be addressed to S. Martens, Neuro Imaging Center, P. O. Box 196, 9700 AD Groningen, the Netherlands (e-mail: s.martens@med.umcg.nl). ing attention over time in a variety of task conditions. The detection or identification of visual targets such as letters, digits, words, and pictures (e.g., Shapiro, Arnell, \& Raymond, 1997), auditory targets such as tones, syllables, and words (e.g., Potter, Chun, Banks, \& Muckenhoupt, 1998), and tactile targets varying in intensity, amplitude, frequency, and location (Hillstrom, Shapiro, \& Spence, 2002) have been studied both within and between modalities (Arnell \& Jolicœur, 1999; Duncan, Martens, \& Ward, 1997; Soto-Faraco et al., 2002). The majority of these studies show a robust $\mathrm{AB}$ effect and suggest that attention is subject to resource limitations at a postperceptual stage in processing.

The restrictions in memory and attention as revealed by the $\mathrm{AB}$ highlight the importance of efficient selection of items occurring at different points in time. It is well known that spatial or symbolic cues can be used to enhance the selection of relevant information in space, as revealed by improvements in the accuracy and speed of detection or discrimination of stimuli presented at cued locations (e.g., Posner, 1980). Given the dynamic nature of the environment, it seems likely that cuing the time of occurrence of an event could also facilitate selection. Thus, it is plausible that not only information about where, but also information about when to expect an event may play an important role in directing one's attention to the external world. From the warning signal literature (for a review, see Niemi \& Nätäänen, 1981), it is known that performance can be improved when a warning signal is presented before an imperative stimulus (see, e.g., Bertelson, 1967; Bertelson $\&$ Tisseyre, 1968). Presumably, the warning signal enables participants to achieve a heightened state of preparation (i.e., it increases alertness), resulting in faster reaction times to the forthcoming stimulus. In this so-called foreperiod effect, alertness is at its height approximately 150 $200 \mathrm{msec}$ after warning signal presentation and then rapidly decays. 
More recently, Nobre and colleagues (e.g., Coull \& Nobre, 1998; Nobre, 2001a, 2001b) have suggested that information about the time interval within which a stimulus might be expected to appear can be used dynamically to direct visual attention. For example, in one condition of the Coull and Nobre study, targets were preceded by an informative cue regarding the temporal interval between cue and target (300 or 1,500 msec). A cuing effect was found such that reaction times (RTs) were generally faster when the cue predicted when the target would occur than when no cue or an invalid cue was provided. Although the cuing effect was much more robust for the short cue-target interval, Coull and Nobre argued that the increase in alertness associated with a temporal cue is not necessarily linked to the moment of its presentation, as is suggested by the time course of the foreperiod effect (e.g., Bertelson, 1967), but that deployment of anticipatory resources is at least partially under flexible cognitive control. Such an interpretation suggests that attention can be directed to points in time in an analogous fashion to regions of space. Interestingly, the temporal cuing task of Coull and Nobre engaged activity in frontoparietal networks, which overlapped extensively with brain areas engaged by spatial cuing tasks. However, compared with brain activity during spatial cuing tasks, a different pattern of hemispheric lateralization was found, with temporal cuing being relatively left instead of right lateralized.

The tasks used by Nobre (2001a, 2001b) required speeded motor responses emphasizing response aspects of temporal cuing. What is lacking at present are studies that investigate whether temporal cuing can also be applied when unspeeded responses are required and when identification accuracy of masked targets is measured instead of RT. In other words, it is currently unknown whether the temporal cuing effects for the above-threshold stimuli presented by Nobre and colleagues can also be found for stimuli that are sometimes below threshold. In the present study, the paradigms of temporal cuing and the $\mathrm{AB}$ were combined to investigate the extent to which individuals can dynamically direct their attention to specific moments in time, possibly overcoming the restrictions in memory and attention, as reflected by the AB.

\section{EXPERIMENT 1}

In the AB paradigm, the time interval or "lag" between two targets is typically varied from trial to trial to measure the time course of interference, and the participant is not informed what the lag of the forthcoming trial will be. In Experiment 1, we contrasted performance in a condition with varying lags with that in a condition in which the lag between the two targets was held constant. A fixed time interval between target stimuli can be considered an implicit temporal cue, enabling participants to predict the moment at which the first target will be followed by the second target. If attention can be oriented toward a particular moment in time, identification accuracy might be enhanced, possibly boosting performance at the difficult short lag, and reducing the AB.

\section{Method}

Participants. Thirty-six volunteers (26 females) from the University of Groningen community, ages $14-25$ (mean $=20.3)$, with normal or corrected-to-normal vision, participated in the experiment and received payment of $€ 5$.

Stimuli and Apparatus. The generation of stimuli and the collection of responses were controlled using MEL 2.01 software (Schneider, 1988) running under native DOS on a Pentium III, 1GHz processor. The participants were tested individually in a dimly lit laboratory room. The stimuli were digits (excluding 1 and 0 ) and uppercase letters (excluding I, O, Q, and v), subtending $0.3^{\circ} \times 0.7^{\circ}$ of visual angle at a viewing distance of approximately $50 \mathrm{~cm}$. The stimuli were presented in black $\left(0.36 \mathrm{~cd} / \mathrm{m}^{2}\right)$ on a gray background $\left(48.2 \mathrm{~cd} / \mathrm{m}^{2}\right)$ on a 15 -in. monitor.

Procedure. The participants were instructed to identify two target letters among a stream of digit distractors, presented one after another at the same central location. Prior to each trial, a fixation cross was presented in the middle of the screen, accompanied by a message at the bottom of the screen instructing the participants to press the space bar to initiate the trial. When the space bar was pressed, the message disappeared immediately. The fixation cross remained on the screen for $650 \mathrm{msec}$. After an additional $100 \mathrm{msec}$, a sequence of 14 distractor digits and two target letters was presented. Each target and distractor was presented for $90 \mathrm{msec}$, resulting in a presentation rate of approximately 11 items per second.

Distractor digits were randomly selected with the constraint that no single digit was presented twice in succession within a trial. The two targets were always different letters. The first target (T1) always appeared as the sixth item in the stream. The second target (T2) followed at a target onset asynchrony (TOA) of either 270 or $720 \mathrm{msec}$, depending on the group to which the participant was assigned. These specific TOAs, also referred to as lag 3 and lag 8, were chosen on the basis of the literature and previous work in our laboratory. At lag 3, in which $\mathrm{T} 2$ followed $\mathrm{T} 1$ after two digits, $\mathrm{T} 2$ is likely to be "blinked" (i.e., not identified), whereas at lag 8 , in which T2 followed T1 after seven digits, T2 is expected to be outside the interval within which an $\mathrm{AB}$ might occur. The participants were randomly assigned to one of three groups: lag 3 , lag 8 , or varying. For the lag 3 group, the TOA was always $270 \mathrm{msec}$. For the lag 8 group, the TOA was always $720 \mathrm{msec}$. In the varying group, the lag (3 or 8 ) varied randomly from trial to trial.

Following the presentation of the RSVP sequence, the participants were asked to type the letters they had seen by using the corresponding keys on the computer keyboard. The participants were instructed to take sufficient time in making their responses to ensure that typing errors were not made. If a letter was not seen, the space bar was to be pressed instead.

The experiment consisted of a practice block of 20 trials and an experimental block of 200 trials, with a short break halfway through the block. Ten additional warm-up trials were given at the start of the experimental block and immediately following the break. The experiment was conducted in one session lasting approximately $30 \mathrm{~min}$.

\section{Results and Discussion}

The percentage correct for each target was computed for each lag. Responses were counted as correct regardless of the order in which they were made. Because performance in the constant time interval (lag 3 and lag 8 groups) condition was measured between subjects (in order to keep conditions constant for a given participant), whereas performance in the varying time interval condition was measured within subjects, it was not possible to analyze the data with one analysis of variance (ANOVA). Instead, $t$ tests were conducted to test for differences between and within the two constant lag groups 
and the varying group for each lag. Table 1 shows performance for T1. Independent samples $t$ tests showed no significant differences in $\mathrm{T} 1$ performance between constant and varying conditions at lag $3[t(22)=.01, S E=$ $3.98, p=.99]$ or lag $8[t(22)=.83, S E=4.67, p=.42]$. Comparisons of lag 3 and lag 8 within the constant condition $[t(22)=.20, S E=4.13, p=.83]$ and within the varying condition $[t(11)=1.97, S E=1.57, p=.08]$ also revealed no significant differences.

Because the $\mathrm{AB}$ is defined as a deficit in reporting a second target after a first, T2 identification was investigated only for those trials on which $\mathrm{T} 1$ was correctly reported. Table 2 shows performance for T2, given that T1 was reported correctly. $t$ tests showed that performance at lag 3 was significantly worse than performance at lag 8 , both when compared between the two constant lag groups $[t(22)=4.33, S E=8.09, p=.000]$ and within the varying group $[t(11)=12.06, S E=2.66, p=.000]$. Thus, both the groups with a constant lag as well as the varying lag group showed an $\mathrm{AB}$. In fact, no significant differences at either lag [lag $3, t(22)=.17, S E=8.74$, $p=.87$; lag $8, t(22)=.89, S E=4.92, p=.38]$ were found between the constant lag groups and the varying lag group.

The results suggest that when the time interval remains constant, the task of identifying the two targets is just as difficult as it is when the interval varies from trial to trial. In principle, a constant time interval gives participants the chance to anticipate and direct their attention to the precise moment when $\mathrm{T} 2$ will be presented. If temporal cuing can improve accuracy in a difficult identification task, an implicit temporal cue such as the constant time interval should have led to better performance in our task. As it turned out, regardless of the lag at which the targets were presented, participants simply did not or could not use the temporal constancy to improve performance.

Table 1

Mean Percentage Correct Report of T1 in Experiment 1 in the Constant and Varying Time Interval Conditions, as a Function of Lag

\begin{tabular}{|c|c|c|c|c|}
\hline \multirow[b]{3}{*}{ Lag } & \multicolumn{4}{|c|}{ Interval } \\
\hline & \multicolumn{2}{|c|}{ Constant } & \multicolumn{2}{|c|}{ Varying } \\
\hline & $M$ & $S E$ & $M$ & $S E$ \\
\hline 3 & 79.8 & 2.69 & 79.8 & 2.93 \\
\hline 8 & 80.6 & 3.14 & 76.8 & 3.46 \\
\hline
\end{tabular}

Table 2

Mean Percentage Correct Report of T2 (Given Correct Report of T1) in Experiment 1 in the Constant and Varying Time Interval Conditions, as a Function of Lag

\begin{tabular}{|c|c|c|c|c|}
\hline \multirow[b]{3}{*}{ Lag } & \multicolumn{4}{|c|}{ Interval } \\
\hline & \multicolumn{2}{|c|}{ Constant } & \multicolumn{2}{|c|}{ Varying } \\
\hline & $M$ & $S E$ & $M$ & $S E$ \\
\hline 3 & 39.8 & 7.45 & 38.3 & 4.56 \\
\hline 8 & 74.8 & 3.16 & 70.4 & 3.77 \\
\hline
\end{tabular}

\section{EXPERIMENT 2}

In Experiment 1, we failed to find a beneficial effect on target identification of keeping constant the time interval between two targets. This finding is consistent with the suggestion that restrictions in attention and memory revealed by the $\mathrm{AB}$ are more or less hard wired and cannot be overcome by using strategic information. However, it may simply be that participants did not effectively use the information that was provided. In the spatial cuing literature, it has also been shown that participants do not always use cue information when trials of a certain type are blocked. For example, Posner, Snyder, and Davidson (1980) compared the effects of blocked cuing and trial-by-trial cuing in a task in which a target stimulus appearing at one of four possible locations was to be detected. In one condition, a spatial cue was provided at the start of each trial, indicating the most probable target location (79\% likely) for that trial. Compared with performance in conditions in which no spatial cue was given and target locations were equally probable, RT decreased significantly. However, no improvement in performance over the uncued condition was found when one location was most likely for a complete block of trials (instead of participants being cued on each trial). That is, no reduction in RT occurred when $79 \%$ of the targets were presented in the same location (out of four possible locations) throughout a block of trials, compared with blocks in which the likelihood of a target was equal for each location (25\%). Thus, participants seemed not to attend to the expected position when they were not cued to do so on each trial.

Posner et al. (1980) concluded that "Knowledge of where a stimulus will occur produces benefits when it is used actively (cued) but not when it is used to maintain a general set (blocked)" (p. 172). This suggests that knowledge of where to expect a target stimulus must be actively or explicitly maintained in working memory, and the same might be true for temporal information. Participants might simply neglect to use the time interval information that is available to them when the time interval between two targets is held constant within a block of trials. Or, in other words, the task of staying prepared for an entire block of trials may be too taxing. One last possibility is that, in their subjective experience, participants were not fully aware of the constant time interval between the two targets because, of course, the second target was often missed.

Experiment 2 was designed to test whether participants can use foreknowledge about the onset interval between two targets when they are explicitly instructed to do so on each trial. In this experiment, the lag ( 3 or 8 ) varied randomly from trial to trial, and participants were informed of the lag of the forthcoming trial on a trialby-trial basis.

\section{Method}

Participants. Twelve new volunteers ( 8 females) from the University of Groningen community, ages $16-27$ (mean $=22.1)$, with 
normal or corrected-to-normal vision, participated in the experiment and received payment of $€ 5$. Data from the 12 participants in the varying condition of Experiment 1 were used to form an "uncued" comparison group.

Stimuli and Apparatus. The stimuli and apparatus were the same as in Experiment 1.

Procedure. As in Experiment 1, the participants were instructed to identify two target letters among a stream of distractor digits. The time interval between the two targets (i.e., the TOA) varied from trial to trial and could be either 270 (lag 3) or $720 \mathrm{msec}$ (lag 8). Prior to each trial, a cue was given to indicate the TOA in that trial. The cue was either a single dash ("-") to indicate a short TOA (lag 3), or a row of three dashes ("---") indicating a longer TOA (lag 8). The temporal information provided by the cue was always valid. The cue was presented in the middle of the screen and also served as a fixation mark. In addition to the cue, a message was displayed at the bottom of the screen instructing the participants to press the space bar to initiate the trial. When the space bar was pressed, the message disappeared immediately, whereas the cue remained on the screen for $750 \mathrm{msec}$. After an additional interval of $100 \mathrm{msec}$, the RSVP stream was presented, as in Experiment 1. The participants were explicitly encouraged to use the cue to prepare for the two targets. The numbers of experimental trials, practice trials, and breaks were the same as in Experiment 1. The experiment was conducted in one session, lasting approximately $40 \mathrm{~min}$.

\section{Results and Discussion}

The percentage correct for each target was computed for each lag. Responses were counted as correct regardless of the order in which they were made. Identification accuracy was compared both between lags and with performance of the varying group (hereafter called the uncued condition) from Experiment 1. Table 3 shows performance on T1. A repeated measures ANOVA performed on T1 accuracy with lag ( 3 or 8$)$ as a within-subjects factor and cue (cued or uncued) as a between-subjects factor showed no significant effect of cue or lag $[F(1,22)=.68$, $\left.M S_{\mathrm{e}}=12.27, p=.42\right]$. However, a significant lag $\times$ cue interaction was found $\left[F(1,22)=4.95, M S_{\mathrm{e}}=12.27, p=\right.$

Table 3

Mean Percentage Correct Report of T1 in Experiment 2 (Cued) in Comparison With the Varying Time Interval Condition of Experiment 1 (Uncued), as a Function of Lag

\begin{tabular}{ccccc}
\hline & \multicolumn{4}{c}{ Condition } \\
\cline { 2 - 3 } Lag & $M$ & & \multicolumn{2}{c}{ Uncued } \\
\cline { 2 - 3 } \cline { 5 - 5 } Cued & & $M E$ & $S E$ \\
\hline 3 & 83.4 & 3.57 & 79.8 & 2.93 \\
8 & 84.8 & 2.77 & 76.8 & 3.46 \\
\hline
\end{tabular}

Table 4

Mean Percentage Correct Report of T2 (Given Correct Report of T1) in Experiment 2 (Cued) in Comparison With the Varying Time Interval Condition of Experiment 1 (Uncued), as a Function of Lag

\begin{tabular}{|c|c|c|c|c|}
\hline \multirow[b]{3}{*}{ Lag } & \multicolumn{4}{|c|}{ Condition } \\
\hline & \multicolumn{2}{|c|}{ Cued } & \multicolumn{2}{|c|}{ Uncued } \\
\hline & $M$ & $S E$ & $M$ & $S E$ \\
\hline 3 & 56.7 & 6.52 & 38.3 & 4.56 \\
\hline 8 & 77.7 & 4.29 & 70.4 & 3.77 \\
\hline
\end{tabular}

.04], such that the difference between cued and uncued conditions was larger at lag 8 than at lag 3 .

Performance for T2, given that T1 was reported correctly, is shown in Table 4. A mixed ANOVA with lag (3 or 8 ) as a within-subjects factor and cue (cued or uncued) as a between-subjects factor showed a significant effect of lag $\left[F(1,22)=126.88, M S_{\mathrm{e}}=66.27, p=.000\right]$, a marginally significant effect of cue $\left[F(1,22)=3.89, M S_{\mathrm{e}}=\right.$ $509.00, p=.06]$, and a significant lag $\times$ cue interaction $\left[F(1,22)=5.58, M S_{\mathrm{e}}=66.27, p=.03\right]$. As can be seen in Table 4, performance was better at lag 8 than at lag 3 for both the cued and the uncued groups, which is consistent with an AB. However, the difference between performance at lag 3 and lag 8 (i.e., the $\mathrm{AB}$ effect) was smaller for the cued than for the uncued group. In order to examine any possible learning effects, a mixed ANOVA with block (1 or 2) and lag (3 or 8) as within-subjects factors and cue (cued or uncued) as a between-subjects factor was conducted. This ANOVA showed no main effect of block $\left[F(1,22)=.53, M S_{\mathrm{e}}=59.11, p=.48\right]$, and no interactions of block with other factors. This indicates that there was no significant change in performance in the second half of the experiment relative to the first half, suggesting that participants quickly learned to make use of the temporal cue and continued using it throughout the experiment.

The major finding from this experiment was that temporal cues can be used to attenuate the AB. Thus, participants can use foreknowledge about target onset interval when explicitly cued to do so on a trial-by-trial basis.

\section{EXPERIMENT 3}

The results of Experiment 2 provide evidence that people can use a cue regarding the time interval between the targets to improve identification performance. When participants were cued (with a single dash ["-"] or three dashes ["--_"] for a short or long interval, respectively) on a trial-by-trial basis as to whether the time interval between the two targets would be short or long, they showed less of an $\mathrm{AB}$ than did individuals who received no cue. The aim of Experiment 3 was to replicate this result within subjects and with a cue that more directly conveys temporal information.

\section{Method}

Participants. Thirty new student volunteers (23 females) from the University of Groningen, ages $18-31$, (mean $=20.3)$ with normal or corrected-to-normal vision participated in the experiment and received course credit for their participation.

Stimuli and Apparatus. The generation of stimuli and the collection of responses were controlled using E-Prime 1.0 software (Schneider, Eschman, \& Zuccolotto, 2002) running under Windows 98 on a PC with a $1.2-\mathrm{Ghz}$ processor. The stimuli were digits (excluding 1 and 0 ) and uppercase consonants (excluding $\mathrm{Q}$ and $\mathrm{v}$ ), subtending $.2^{\circ} \times .3^{\circ}$ of visual angle at a viewing distance of approximately $75 \mathrm{~cm}$. The stimuli were presented in black $\left(1.5 \mathrm{~cd} / \mathrm{m}^{2}\right)$ on a white background $\left(165 \mathrm{~cd} / \mathrm{m}^{2}\right)$ on a 15 -in. TFT monitor at a refresh rate of $75 \mathrm{~Hz}$.

Procedure. As in Experiments 1 and 2, the participants were instructed to identify two target letters among a stream of distractor 
digits. The time interval between the two targets varied from trial to trial and could be either $270 \mathrm{msec}$ (lag 3) or $720 \mathrm{msec}$ (lag 8). Two conditions were contrasted, one with cuing and one without. In the cued condition, a cue consisting of two briefly presented dashes, with the interval between them matching the interval between the two targets in the forthcoming trial, was presented prior to each trial. In the uncued condition, the task was the same, but no cue was presented. The experiment was conducted in two sessions, which took place at least 2 weeks apart. Half of the participants completed the cued condition in Session 1 and the uncued condition in Session 2; the other half of the participants completed the conditions in the reverse order.

Prior to each trial, a fixation cross was presented in the middle of the screen, accompanied by a message at the bottom of the screen instructing the participants to press the space bar to initiate the trial. In the uncued condition, the message disappeared immediately when the space bar was pressed, the fixation cross remained on the screen for $750 \mathrm{msec}$, and after an additional $100 \mathrm{msec}$, the RSVP stream was presented. In the cued condition, both the message and the fixation cross disappeared from the screen when the space bar was pressed. After $200 \mathrm{msec}$, a single dash was presented twice in succession in the middle of the screen, for $90 \mathrm{msec}$ each time with a TOA of either $270 \mathrm{msec}$ (corresponding to lag 3) or $720 \mathrm{msec}$ (corresponding to lag 8) between the two presentations. After $1,100 \mathrm{msec}$, the RSVP stream containing the two targets was presented. The participants were explicitly instructed to use the cue to enhance their identification accuracy.

Both the RSVP stream and the rest of the procedure were identical to those of the conditions of Experiments 1 and 2 in which the lag was varied from trial to trial. Each session lasted approximately $45 \mathrm{~min}$.

\section{Results and Discussion}

The percentage correct for each target was computed for each lag. The responses were counted as correct regardless of the order in which they were made. Table 5 shows performance for $\mathrm{T} 1 .{ }^{1}$ A repeated measures ANOVA performed on T1 accuracy with lag (3 or 8) and cue (cued or uncued) as within-subjects factors showed no significant effect of lag $\left[F(1,29)=1.04, M S_{\mathrm{e}}=7.68, p=.32\right]$. However, a significant effect of cue was found $[F(1,29)=6.06$, $\left.M S_{\mathrm{e}}=25.07, p=.02\right]$, as was a lag $\times$ cue interaction

Table 5

Mean Percentage Correct Report of T1 in Experiment 3 in the Cued and Uncued Conditions, as a Function of Lag

\begin{tabular}{|c|c|c|c|c|}
\hline \multirow[b]{3}{*}{ Lag } & \multicolumn{4}{|c|}{ Condition } \\
\hline & \multicolumn{2}{|c|}{ Cued } & \multicolumn{2}{|c|}{ Uncued } \\
\hline & $M$ & $S E$ & $M$ & $S E$ \\
\hline 3 & 92.6 & 1.09 & 89.0 & 1.66 \\
\hline 8 & 91.8 & 1.20 & 90.9 & 1.47 \\
\hline
\end{tabular}

Table 6

Mean Percentage Correct Report of T2 (Given Correct Report of T1) in Experiment 3 in the Cued and Uncued Conditions, as a Function of Lag

\begin{tabular}{|c|c|c|c|c|}
\hline \multirow[b]{3}{*}{ Lag } & \multicolumn{4}{|c|}{ Condition } \\
\hline & \multicolumn{2}{|c|}{ Cued } & \multicolumn{2}{|c|}{ Uncued } \\
\hline & $M$ & $S E$ & $M$ & $S E$ \\
\hline 3 & 70.8 & 3.60 & 62.4 & 3.69 \\
\hline 8 & 89.3 & 1.58 & 87.5 & 1.88 \\
\hline
\end{tabular}

$\left[F(1,29)=7.51, M S_{\mathrm{e}}=6.92, p=.01\right]$. The difference between the cued and the uncued conditions was larger at lag 3 than at lag 8, although all differences were relatively small.

The performance for $\mathrm{T} 2$, given that $\mathrm{T} 1$ was reported correctly, is shown in Table 6. A repeated measures ANOVA with lag and cue as within-subjects factors showed significant effects of lag $\left[F(1,29)=58.36, M S_{\mathrm{e}}=243.56, p=\right.$ $.000]$ and cue $\left[F(1,29)=15.11, M S_{\mathrm{e}}=51.33, p=.001\right]$ and a significant lag $\times$ cue interaction $\left[F(1,29)=10.87, M S_{\mathrm{e}}=\right.$ $29.76, p=.003]$. As can be seen in Table 6, the difference in T2|T1 accuracy at lag 3 versus lag 8 was smaller in the cued than in the uncued condition.

As in Experiment 2, cuing the temporal onset between $\mathrm{T} 1$ and $\mathrm{T} 2$ reduced the magnitude of the $\mathrm{AB}$. This result allows us to conclude that both symbolic (length of line) and more direct (interval between the first and second presentations of a dash) information about the temporal interval between two targets can help in overcoming the restrictions in working memory and attention revealed by the AB.

\section{GENERAL DISCUSSION}

The goal of the present study was to examine whether people can use strategic information to overcome the limitations in attention and memory reflected by the $\mathrm{AB}$. In three experiments, participants were provided with explicit (Experiments 2 and 3 ) or implicit (Experiment 1) information on when to expect two target letters in an RSVP stream of nontarget digits. In Experiment 1, the accuracy of identifying the targets was found not to depend on whether the time interval $(270$ or $720 \mathrm{msec})$ between the two targets varied from trial to trial or was kept constant throughout the experiment.

In contrast, in Experiments 2 and 3, in which the time interval between the two targets varied from trial to trial as in a standard $\mathrm{AB}$ paradigm, the $\mathrm{AB}$ was attenuated when a cue indicating the temporal separation between the targets in the upcoming trial was given. The results suggest that, despite the strong restrictions in memory and attention that are typically revealed by the $\mathrm{AB}$, some strategic control over the allocation of resources is possible.

The present results show that temporal cues can affect identification accuracy when responses are nonspeeded, extending previous findings from studies on temporal cuing in speeded-response tasks (e.g., Nobre, 2001b). Moreover, the present experiments suggest that temporal cues will only be effective in orienting attention when they are presented on a trial-by-trial basis, which presumably encourages participants to actively maintain the cues in working memory. A similar conclusion was reached by Posner et al. (1980) in the domain of spatial cuing, based on the finding that spatial cues were ineffective when entire blocks, instead of individual trials, were cued.

The finding in Experiment 1 that the $\mathrm{AB}$ was equally large in the constant and varying conditions is especially interesting in that it shows that varying the lag from trial 
to trial does not contribute to the $\mathrm{AB}$. In other words, there is no benefit to performance from repeating a given lag from one trial to the next. Repetition effects are commonly found in a range of tasks from speededchoice reaction tasks (e.g., Pashler \& Baylis, 1991) to visual search (e.g., Müller \& Found, 1996; Maljkovic \& Nakayama, 2000; Olivers \& Humphreys, 2003). In the case of an AB task, one might thus expect a benefit of repeating lag even though the particular targets to be identified vary from trial to trial. As mentioned earlier, blocking trial type did not benefit performance. In addition, a comparison of repetition (e.g., a lag 3 trial following a lag 3 trial) and nonrepetition (e.g., a lag 3 trial following a lag 8 trial) trials in the varying condition of Experiment 1 revealed no differences in performance.

The fact that identification performance in Experiment 1 did not depend on whether the lag varied or was kept constant also implies that a single time interval of approximately $300 \mathrm{msec}$ is sufficient to induce an AB. That is, one lag might be sufficient in many AB studies, substantially reducing the number of trials required to investigate the $\mathrm{AB}$ in, for instance, patients, elderly people, or children in both behavioral and brain-imaging studies.

Finally, an important finding from Experiments 2 and 3 is that the improved performance for T2 presented at a short interval did not come at a cost to T1. In other words, the temporal cuing effect does not appear to be the outcome of a bias to select T2 over T1 when the two targets occur close together in time.

\section{The Locus of Temporal Cuing Effects}

Early accounts of the AB included the idea of an attentional window or gate that is opened when a target is encountered (cf. Raymond et al., 1992) and then shut to exclude distractors. According to such an account, the $\mathrm{AB}$ is the result of a sluggish reopening of an attentional gate for the second target. It could be argued that when observers know that the interval between two targets will be short, they adopt a strategy of keeping the attentional gate open to allow processing of both T1 and T2. However, such a strategy would result in the admittance not only of T2 in the same attentional episode as T1, but of the distractors presented between $\mathrm{T} 1$ and $\mathrm{T} 2$ as well. According to most models of the AB (e.g., Chun \& Potter, 1995; Potter, Staub, \& O’Connor, 2002; Raymond, Shapiro, \& Arnell, 1995; Shapiro, Raymond, \& Arnell, 1994), the entry of the additional items should come at a cost to processing of the targets. Because the improvement in identification of the second target did not come at a cost of identifying T1, such an account of the temporal cuing effect does not seem plausible.

One possible explanation of the temporal cuing effect might be that temporal cues enhance the perceptual description of target items - and target templates. That is, information about the expected time of occurrence of a target might function as a perceptual feature or extra attribute of a target, along with other perceptual features such as form, color, and so forth. Temporal cues might thus be useful in distinguishing relevant from irrelevant information and in selecting targets from nontargets. The interference model of Shapiro et al. (1994; see also Raymond et al., 1995) provides a possible mechanism by which temporal information could influence identification performance. Temporal cues might play a role in the assignment of weights if they provide additional information that can be used to distinguish targets from nontargets. In this view, both targets might receive a high weight, not at the expense of each other but at the expense of the distractors, whose weights will be diminished. As a result, distractors will be less likely to enter visual short term memory, and the competition for selection in VSTM will also be diminished due to larger differences in target versus nontarget weights. When the interval between $\mathrm{T} 1$ and $\mathrm{T} 2$ is short, a temporal cue might effectively influence the relative weight of $\mathrm{T} 2$, such that identification performance for that target can be significantly enhanced. At a long target-onset interval, the relative weight of $\mathrm{T} 2$ is already high, such that no additional cuing benefit would be expected. This pattern of behavioral results was observed in the experiments reported here.

Turning back to the temporal cuing work of Nobre and colleagues (Griffin, Miniussi, \& Nobre, 2002; Miniussi, Wilding, Coull, \& Nobre, 1999; Nobre, 2001b), these authors found that the $\mathrm{P} 3$ component of the event-related potential in response to a target had a reduced latency and an enhanced amplitude when the target was temporally cued. Since the P3 component is associated with the updating of working memory, it could be argued that the findings of Nobre and colleagues suggest a late locus of temporal cuing, at a level of processing that corresponds to Stage 2 rather than to Stage 1. However, the enhanced P3 component could merely reflect the consequence of temporal cuing effects that took place at an earlier processing stage, rather than the direct reflection of the cuing effects themselves. In other words, each item presented in the RSVP stream might induce a P3 component that is as large as the relative strength of its weight. This prediction seems to fit well with the finding that the P3 component is reduced or absent when T2 is "blinked" (e.g., Kranczioch, Debener, \& Engel, 2003; Rolke et al., 2001; see also Shapiro, Schmitz, Martens, Hommel, \& Schnitzler, 2005).

\section{Conclusion}

We have demonstrated that strategic information can be used to partially overcome the attentional restrictions reflected by the AB. Presumably, temporal cues can influence the allocation of resources by adding temporal information to the perceptual description of a target. This information can be used to filter relevant targets from irrelevant nontargets, resulting in enhanced accuracy in reporting targets. If attention has a limited capacity, the observed benefit for T2, with T1 performance remaining intact, can most easily be explained by assuming that there was a cost to the processing of the distractors. According to the interference theory of Shapiro et al. 
(1994), the relative strength of the target weights in comparison with those of the distractors reduces the chance that the distractors enter working memory, leaving more resources available for the consolidation of the targets, thus increasing the chance of successful $\mathrm{T} 2$ report.

The fact that participants profited from temporal information only when it was explicitly presented to them on a trial-by-trial basis provides additional support for the view that the temporal cuing effect observed here has a strategic or top-down origin. Active maintenance of temporal cues in working memory might contribute to the description of target templates (see, e.g., Duncan \& Humphreys, 1989), which presumably play a crucial role in the selection of targets from nontargets.

\section{REFERENCES}

Arnell, K. M., \& Jolicceur, P. (1999). The attentional blink across stimulus modalities: Evidence for central processing limitations. Journal of Experimental Psychology: Human Perception \& Performance, 25, 630-648.

BERTELSON, P. (1967). The time course of preparation. Quarterly Journal of Experimental Psychology, 19, 272-279.

Bertelson, P., \& Tisseyre, F. (1968). The time course of preparation with regular and irregular foreperiods. Quarterly Journal of Experimental Psychology, 20, 297-300.

BROADBENT, D. E., \& BROADBENT, M. H. P. (1987). From detection to identification: Response to multiple targets in rapid serial visual presentation. Perception \& Psychophysics, 42, 105-113.

Chun, M. M., \& PotTer, M. C. (1995). A two-stage model for multiple target detection in rapid serial visual presentation. Journal of Experimental Psychology: Human Perception \& Performance, 21, 109-127.

Coull, J. T., \& Nobre, A. C. (1998). Where and when to pay attention: The neural systems for directing attention to spatial locations and to time intervals as revealed by both PET and fMRI. Journal of Neuroscience, 18, 7426-7435.

Duncan, J., \& HumphreYs, G. W. (1989). Visual search and stimulus similarity. Psychological Review, 96, 433-458.

Duncan, J., MarTens, S., \& Ward, R. (1997). Restricted attentional capacity within but not between sensory modalities. Nature, 379, 808-810.

Griffin, I. C., Miniussi, C., \& Nobre, A. C. (2002). Multiple mechanisms of selective attention: Differential modulation of stimulus processing by attention to space or time. Neuropsychologia, $\underline{\mathbf{4 0}}, \underline{2325-}$ 2340 .

Hillstrom, A. P., Shapiro, K. L., \& Spence, C. (2002). Attentional limitations in processing sequentially presented vibrotactile targets. Perception \& Psychophysics, 64, 1068-1082.

KrANCZIOCH, C., Debener, S., \& Engel, A. K. (2003). Event-related potential correlates of the attentional blink phenomenon. Cognitive Brain Research, 17, 177-187.

LuCK, S. J., Vogel, E. K., \& SHAPIRo, K. L. (1996). Word meanings can be accessed but not reported during the attentional blink. Nature, $\mathbf{3 8 3}$, 616-618.

MaljKovic, V., \& Nakayama, K. (2000). Priming of popout: III. A short-term implicit memory system beneficial for rapid target selection. Visual Cognition, 7, 571-595.

Martens, S., Wolters, G., \& VAN RAamsdonk, M. (2002). Blinks of the mind: Memory effects of attentional processes. Journal of Experimental Psychology: Human Perception \& Performance, 28, 1275-1287.

Miniussi, C., Wilding, E. L., Coull, J. T., \& Nobre, A. C. (1999). Orienting attention in time: Modulation of brain potentials. Brain, 122, 1507-1518.

Müller, H. J., \& Found, A. (1996). Searching for unknown feature targets on more than one dimension: Investigating a "dimensionweighting" account. Perception \& Psychophysics, 58, 88-101.
Niemi, P., \& NÄÄtÄnen, R. (1981). Foreperiod and simple reaction time. Psychological Bulletin, 89, 133-162.

Nobre, A. C. (2001a). The attentive homunculus: Now you see it, now you don't. Neuroscience \& Biobehavioral Reviews, 25, 477-496.

Nobre, A. C. (2001b). Orienting attention to instants in time. Neuropsychologia, 39, 1317-1328.

Olivers, C. N. L., \& Humphreys, G. W. (2003). Attentional guidance by salient feature singletons depends on intertrial contingencies. Journal of Experimental Psychology: Human Perception \& Performance, 29, 650-657.

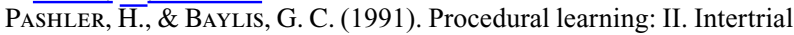
repetition effects in speeded-choice tasks. Journal of Experimental Psychology: Learning, Memory, \& Cognition, 17, 33-48.

PosNer, M. I. (1980). Orienting of attention. Quarterly Journal of Experimental Psychology, 32, 3-25.

Posner, M. I., Snyder, C. R. R., \& Davidson, B. J. (1980). Attention and the detection of signals. Journal of Experimental Psychology: General, 109, 160-174.

Potter, M. C., Chun, M. M., Banks, B. S., \& Muckenhoupt, M. (1998). Two attentional deficits in serial target search: The visual attentional blink and an amodal task-switch deficit. Journal of Experimental Psychology: Learning, Memory, \& Cognition, 24, 979-992.

Potter, M. C., Staub, A., \& O'Connor, D. H. (2002). The time course of competition for attention: Attention is initially labile. Journal of Experimental Psychology: Human Perception \& Performance, 28, $1149-1162$.

RAYMOND, J. E., Shapiro, K. L., \& Arnell, K. M. (1992). Temporary suppression of visual processing in an RSVP task: An attentional blink? Journal of Experimental Psychology: Human Perception \& Performance, 18, 849-860.

RaYMOND, J. E., Shapiro, K. L., \& Arnell, K. M. (1995). Similarity determines the attentional blink. Journal of Experimental Psychology: Human Perception \& Performance, 21, 653-662.

Rolke, B., Heil, M., Streb, J., \& Hennighausen, E. (2001). Missed prime words within the attentional blink evoke an N400 semantic priming effect. Psychophysiology, 38, 165-174.

SCHNEIDER, W. (1988). Micro Experimental Laboratory: An integrated system for IBM-PC compatibles. Behavior Research Methods, Instruments, \& Computers, 20, 206-217.

Schneider, W., Eschman, A., \& Zuccolotto, A. (2002). E-Prime user's guide. Pittsburgh: Psychology Software Tools.

Shapiro, K. L., Arnell, K. M., \& Raymond, J. E. (1997). The attentional blink: A view on attention and a glimpse on consciousness. Trends in Cognitive Sciences, 1, 291-296.

Shapiro, K. L., RAYMOND, J. E., \& ARNELL, K. M. (1994). Attention to visual pattern information produces the attentional blink in rapid serial visual presentation. Journal of Experimental Psychology: Human Perception \& Performance, 20, 357-371.

Shapiro, K. L., Schmitz, F., MARTENS, S., Hommel, B., \& SchnitzLER, A. (2005). The neural correlates of temporal attention. Manuscript submitted for publication.

Soto-Faraco, S., Spence, C., Fairbank, K., Kingstone, A., HillStrom, A. P., \& Shapiro, K. (2002). An attentional blink between vision and touch. Psychonomic Bulletin \& Review, 9, 731-738.

Vogel, E. K., LucK, S. J., \& Shapiro, K. L. (1998). Electrophysiological evidence for a postperceptual locus of suppression during the attentional blink. Journal of Experimental Psychology: Human Perception \& Performance, 24, 1656-1674.

\section{NOTE}

1. Report of both T1 and T2 was higher in Experiment 3 than in Experiments 1 and 2, although the display times were nominally the same. Pilot work indicated that this was most likely due to differences in the fonts and monitors used. Note that the basic hallmark of the data (i.e., the $\mathrm{AB}$ ) was found in all cases.

(Manuscript received October 17, 2003; revision accepted for publication June 4, 2004.) 